\title{
Globalization of Education: Online Teaching Russian as a Foreign Language in a Pandemic Condition
}

\author{
Svetlana L. Savilova ${ }^{1,{ }^{*}}$, Anna A. Kropotkina ${ }^{1}$, and Yevgenia $V$. Kokhanovskaya ${ }^{1}$ \\ ${ }^{1}$ I. M. Sechenov First Moscow State Medical University, Russian Federation
}

\begin{abstract}
.
Research background: In connection with the pandemic situation in the world, higher education had to find a solution to fulfill its obligations and end the academic year. The transition to a digital educational format has allowed universities to fulfill their obligations to provide educational services in full. The article dwells on the main concepts, models and characteristic features of modern distance learning. The relevance of distance learning technologies is substantiated, with the emphasis on the specific organization of the educational process, due to those technologies. Purpose of the article: The aim of the authors was to investigate into the expansion of online learning functions as a tool of the educational process, as well as into the ways to preserve and increase student motivation to study in the situation of distance education.

Methods: Methods are proposed for creating a virtual learning environment based on: resorting to the material from various Internet sources; giving online lectures and consultations; working out tests; using an integration model, a convertible interactive database and a complex approach with the application of multiple resources for passing on and consolidating knowledge, as well as for rating students' academic performance.

Findings \& Value added: Distance learning is a modern reality, which, as an important part and complement to the traditional form of the learning process of a modern student, expands the possibilities of classical university education.
\end{abstract}

Keywords: COVID-19; distance learning; foreign language; motivation

JEL Classification: $A 3$

*Corresponding author: $\underline{\operatorname{sspp} @ \text {,bk.ru }}$ 


\section{Introduction}

While COVID-19 may not have been entirely unanticipated in the epidemiological community, no one in the business community appears to have anticipated it (i.e., placed a probability on its happening) [1].

At the present time COVID-19 is a global emergency. The high mortality rate and the rapid spread of this disease had a significant impact on the psychological state of people [2]. Countries around the world have suffered widespread disruption from the COVID-19 pandemic. Tens of millions have been infected and economies have suffered severe downturns [3].

Infamous force majeure events, occurring in the world, have contributed to modernizing the "online learning" form and developing an integration set of methods for teaching foreign students, and, as a consequence, led to the term "online education"(OE) which should be understood as an improved form of distance learning, involving: the use of presentations in the PowerPoint environment, testing programs and the development of electronic courses on various platforms as a single integration model. In the course of training, the functions of $\mathrm{OE}$ as a tool of the educational process were expanded, which made it possible for teachers to consider different levels of the students' academic excellence during webinars, focusing on the results achieved by the students on the Moodle and Stepic platforms of education. It can be said that a shift in priorities is being observed while evaluating the role of online learning in the educational process. Thus, online learning appears to cease to perform an auxiliary function and gradually begins to play a leading role in the modern education system.

Another important task of distance learning is to maintain and enhance students' motivation to study in the current situation. To implement this, the authors suggest optimizing the work with bilingual students through using existing educational platforms in the conditions of distance learning.

Currently, online learning is rapidly developing in Russia, due to the application of modern technologies. These days,' in the context of the COVID-19 coronavirus pandemic, online learning is becoming the most accessible form of education. Universities worldwide have been quarantined' [4]. Almost all Russian universities 'switched to distance learning from March 16, 2020' [5].

In the conditions of the information society, along with traditional forms of education, modern methods are increasingly applied, based on such technologies as distance learning with the use of webinars focused on students' individual needs and their level of academic achievements, which makes it possible to make the educational process more flexible, universal and personality oriented.

With the development of information technologies and local networks, new learning opportunities have arisen, which allows to maintain the educational process at the proper level.

Every era seems to experience painful disruptions of normalcy. As with past traumatic events, analyzing how businesses reacted to the pandemic offers a unique opportunity to build knowledge [6].

\subsection{Literature Review}

When researching the problems of higher education, globalization and internationalization are increasingly popular terms. Today, we face a new milieu of structural reshaping of the global economic system [7]. 
Globalization can be defined as a process of intensification of cross-border social interactions due to declining costs of connecting distant locations through communication and the transfer of capital, goods, and people [8].

There is no consensus on the impact of globalization processes on education. Some researchers argue that globalization, the Internet, and the scientific community will level the playing field in the new age of knowledge interdependence. Other researchers note that globalization means both worldwide inequality [9].

In our opinion, the processes of globalization have had a significant impact on the use of the latest technologies in education.

Modern methodologists and researchers investigate into online learning methods and the ways of their improvement. This urgent topic is also studied in foreign literature. For example, Luis Miguel Dos Santos [10] points to the fact that the search for optimal and effective teaching methods and strategies is an integral part in teaching foreign languages.

Online learning is becoming increasingly popular nowadays. In the new digital age, according to Reni Puspitasari Dwi Lestariyana and Handoyo Puji Widodo [11], an online environment is familiar to modern students with their vast experience in the actual use of digital technologies through such popular Internet resources as Instagram, Facebook, blogging and WhatsApp.

This is why researchers are now dealing with online learning issues. Thus, Murdoch, Matthew $[12,13]$ noted that today, humanity is passing the dawn of learning, based on modern technologies. This type of learning is an affordable means of spreading ideas, innovations and education all over the world. According to the researcher, the abundance of information search options have brought about an enormous popularity in education of virtual classes and other similar online learning platforms [12].

Nowadays, there is a continuous improvement of existing distance learning tools. New forms have a number of advantages, which, according to Bowen, William G., have led to a sufficient improvement of university infrastructure and saved a lot of time for obtaining new information [14]. N. P.L. Nariyati, Sudirman, N.P. A. Pratiw also pay attention to the rapid changes in the learning process [15]. They note that, in the digital age, constantly developing mobile strategies play a significant role in that process, allowing its continuous improvement.

Chartrand, R. [16] notes that modern technologies provide unlimited access to educational materials for everyone. This fact greatly facilitates the educational process and makes it accessible to a wide circle of persons.

A similar point of view is expressed by Nadiran Tanyeli [17]. The researcher believes that using the Internet as a tool in teaching English makes the learning process more interesting, primarily in relation to those studying a foreign language. The author points out that higher educational institutions increasingly deal with the development of online language programs.

Currently, the influence of new educational forms on the student motivation for studying is being examined as well. Muhammad Dafit Pitoyo, Sumardi, Abdul Asib [18] emphasise that in the 21 st century there is a downward trend in the role of traditional forms of education. In their study, the authors showed that students, with their enhanced motivation, began to study more intensively after passing game tests on the Quizizz free learning platform.

Sanchez, R. A., A.D. Hueros [19], Machado, M. E. Tao [20] and other authors studied the Moodle education platform. In their research, Carolina Costaa, Helena Alvelosa, Leonor Teikheigaa [13] aimed at analyzing the functionality and tools of the Moodle platform used by students, They noted that this online platform opens up many opportunities for students to learn effectively. Thus, the Moodle platform adopted at the University of Aveiro (UA) 
contains modules that allow to create education resources, communicate between participants in the process of learning, give an objective assessment of activities, etc.

\section{Methods}

The current situation in higher education shows that it has become vitally important to conduct classes with the application of new information technologies. It should be noted that the introduction of online learning in education does not involve the exclusion of traditional teaching methods. Distance learning simply complements them. The main goal of online learning is to create sustainable student motivation for studying through the active participation of both students and teachers in the education process. To provide a qualitative improvement in the results of educational activities is only possible if the accumulated methods, personal experience and modern technologies are wisely combined.

The obvious benefits of online learning are as follows: differentiated and personalized education for all students (including those with disabilities, considering territorial accessibility of education in the country's rated universities, etc.); interactivity; quality of tests; justification for the application of visual, audio and video materials; the opportunity to resort to online learning in the work with gifted students; remote participation in Olympiads, competitions, conferences.

The main innovative qualities of online learning include:

1. Need for providing all the components of the educational process: obtaining information, practical training, validation (academic performance monitoring).

2. Interactivity that allows to significantly expand the opportunities for independent educational work, due to active-activity forms of training.

3. The possibility of more complete learning outside the classroom. Completeness of training is emphasized intentionally. This is not about searching for and getting text information from remote sources. Completeness in this case implies those training activities outside the classroom that previously could only be carried out in a university class: the study of new material on a subject basis, ongoing monitoring of academic performance with assessment and conclusions, preparation for exams, and many other things, up to the collective training work of remote users [21].

The teaching method is understood as a didactic category that gives a theoretical idea of the system of norms of interaction between teacher and student to achieve shared learning goals. Online learning methods result in a virtual learning environment that includes various Internet sources, online lectures and consultations, test creation. Students and teaching staff, whose interaction is carried out with the help of modern telecommunications tools, act as constituent parts of online learning. An important integrated factor in distance learning is a set of pedagogical methods and techniques used in the educational process. These are, in the first place, interactive databases; electronic journals; computer training programs (electronic textbooks, grammar simulators, e-courses for preparing for the Certificate of Proficiency in the foreign language examination, in compliance with the standards). A special role in online learning is played by web conferences that allow all the participants of the discussion to conduct an active polylogue, which is of great didactic value.

The team of authors suggests the application of a comprehensive approach to teaching Russian as a foreign language. It is not possible to test with a single resource all the competencies required to pass the exam successfully.

The Stepic Internet platform was used for studying vocabulary and grammar of Russian as a foreign language. For the successful study of grammar, two courses were developed: one for beginners (https://stepik.org/course/60571/syllabus), the other for advanced students (https://stepik.org/course/59769/syllabus). All tasks and theoretical material were 
formed strictly according to the standard of certificates 1 and 2 in Russian as a foreign language.

After learning the visually presented theoretical material, the students are asked to carry out different types of tasks so that they consolidate the acquired skill: the 'Compliance Test' is an example, in which the student is asked to choose the correct answer by moving the word up or down and placing it opposite its 'own' pair. This test results in composing a dialogue, translating a certain word, finding the grammatical correspondence of parts of speech, and so on. In another 'Omissions' test, one needs to enter the correct word in the correct grammatical form instead of the omitted one. Here, the skill of building a sentence is formed, which leads to the improvement of written speech. A table task looks like a table in which the student puts a tick by a word in the desired column, thus training and reinforcing, for example, the skill of the correct use of gender, number or case. Also, a standard example of a test is offered, in which, with a single click, the right one is chosen from several options (multiple choice). In addition, the possibility to use audio files allows novice students to improve pronunciation by training, repeatedly, a particular sound, word, as well as accentuation in words, intonation structures, etc.

The Russian language course "Advanced level" is designed to master a skill in preparing for and successfully passing the Certificate examination, namely, on 5 subtests: "Vocabulary. Grammar"; "Writing"; "Reading"; "Speaking; "Listening". All tasks in these subtests are similar to those that will be given in the exam, which lets every students assess their progress and level of academic excellence. Thus, this training system is aimed at revising the previously studied material, mastering new training material and preparing for the exam, in accordance with the Certificates' requirements. For students, the courses are free of charge.

The undeniable advantage of the courses is that students choose the most convenient time and place to study the topic, which is of importance in the current situation.

The authors' team used the ZOOM Internet platform to master speaking and listening skills. This platform provides the widest opportunities for the organizer to hold a video lesson including the possibility to:

- see the student (opportunity to turn on the video of the learner);

- divide the group into subgroups for training dialogues and monologues;

- use the 'virtual' board;

- display the screen of the teacher's laptop;

- send files to students;

- organize student chats.

On the above-mentioned platform, 'classroom' activities are held with the application of such methods of work as a survey, monologue, and conversation. During the lesson, the student can ask questions directly to the teacher.

To master writing skills, the above-mentioned Russian language course, 'Advanced level', created on the Stepic platform, is used. Based on the text library of mini texts, learners are to compose a monologue in writing, where they need to identify the intentions, inherent in the text written by them (for example, give a recommendation, characterize a person, etc.). Besides, when writing a monologue, students should resort to lexical and grammatical means of various functional styles of the Russian language. The results are also discussed at a webinar by the teacher and other students.

To secure the preparatory work, with a view to passing the subtest in 'Writing' successfully, the participants of the 'Advanced level ...' course are equipped with theoretical knowledge of writing various types of letters in Russian: personal, business, and others. In the practical part, the students should write them strictly in the format of "Russian letter". 
Along with the above-mentioned platforms, the University widely uses the "Moodle" system. This platform contains electronic educational resources (e-learning resources) for each course. These resources are diverse: from mastering a certain skill to monitoring student attendance at webinars and conferences.

On an e-learning resource, the University staff post assignments that the student is to complete after the webinar, which is the so-called second part of the lesson. The possibility to adjust tasks for groups of different levels is a definite plus of this resource.

To monitor attendance, the teacher places a link to a webinar in the e-learning resource system. Clicking on this link, the students find themselves 'in a language classroom', with the system 'seeing' the percentage of student attendance at webinars, thus motivating the students not to miss classes.

To enhance the students' motivation for studying, it is recommended that the University organize a point-rating system. The students should know that, in order to be admitted to a test or exam, they are to earn a minimum number of points composed of attending classes, completing homework, preparing reports, etc., that is, each type of activity of the student must be evaluated. In order to get an excellent mark, students realize that they have to attend all classes of the course.

E-learning resource makes it possible to accommodate various types of classes. We recommend using this resource to develop reading skills. For each lesson, the teacher places the text and the test task to it.

\section{Results}

The proposed method of student online learning not only guarantees quality preparation for exam or for central testing, but also, under difficult circumstances (for example, during a pandemic), contributes to the effective conducting of classes in the subjects studied.

\section{Discussion}

After three months of work in a pandemic condition, the authors' team conducted an online survey. Some 250 students have answered the three questions: 1. What do you like about online learning? 2. What do you not like about online learning? 3. What are your wishes and suggestions?

1. Advantages of this method of teaching were highlighted:

-mobility;

-versatility;

-opportunity for students with disabilities to study;

-ability to choose courses from any University in the world and work out one's own additional training program;

- instructing foreign students without their having to leave their country;

-possibility for multiple viewing of lectures and webinars;

-prospect of creating a future global 'online University'.

2. Disadvantages:

-absence of direct communication between the teacher and the student;

- Time Zones;

-excessive workload of students with homework;

- adhering to the class schedule;

-demand for a laptop and high-speed Internet.

3. Suggestions:

- transferring of some elective, or limited, courses to online learning format; 
-transferring, for students who are inadequately trained, of part of classes to online education, with the obligatory formation of grammar skills, based on 'electronic textbooks';

-holding online seminars on language training for the students who speak the language at level B1-B2, which will free up additional time for them to study major subjects;

- making a semester lesson plan and familiarizing students with it;

- recording lecture material on video for advanced students and providing access to that material, so that they can prepare for an online class in advance.

- arranging for consultation hours, where students can ask questions, discuss coursework, etc.

- working out, by the University, personal accounts of student and of teacher, containing necessarily electronic magazines and chat between the teacher and the student.

\section{Conclusion}

Often, advanced skills are needed where individuals are faced with unfamiliar situations, with little guidance from previous encounters [22].

Modern times dictate their rules in all areas of activity. We need to admit that distance, or online, learning, is becoming a reality of higher education. However, this will require retraining of the teaching staff, adjusting training programs, equipping universities with modern means for distance learning, connecting IT- specialists to create e-courses, journals, data accounting and student identification.

Distance learning is a modern reality, without which education of the XXI century is unthinkable. However, it should be noted that online learning can only be an additional part to the traditional form of education, without replacing it by $100 \%$.

Despite the fact that distance education is popular and universally accepted, all the surveyed agreed that it cannot substitute for live communication between student and teacher, nor make up for student friendship or an atmosphere of academic environment with its team spirit. Distance learning is designed to complement and expand the possibilities of classical university education.

\section{References}

1. Foss, N. J. (2020). Behavioral strategy and the COVID-19 disruption. Journal of Management, 46(8), 1322-1329..

2. Feng, Y., Zong, M., Yang, Z., Gu, W., Dong, D., \& Qiao, Z. (2020). When altruists cannot help: the influence of altruism on the mental health of university students during the COVID-19 pandemic. Globalization and Health, 16(1), 1-8.

3. Ketchen Jr, D. J., \& Craighead, C. W. (2020). Research at the Intersection of Entrepreneurship, Supply Chain Management, and Strategic Management: Opportunities Highlighted by COVID-19. Journal of Management, 46(8), 1330-1341.

4. The Cancellation of Mass Events in Moscow, the Closure of Schools Around the World and More than 1000 Patients in the United States: Epidemic News COVID-19. Retrieved from http: https://www.forbes.ru/tehnologii/394723-otmena-massovyhmeropriyatiy-v-moskve-zakrytie-shkol-po-vsemu-miru-i-bolshe-1000

5. Students Face Remote Accommodation. Retrieved from http: https://www.kommersant.ru/doc/4292688

6. Ahlstrom, D., \& Wang, L. C. Temporal Strategies and Firms' Speedy Responses to COVID-19. Journal of Management Studies.. 
7. Petricevic, O., \& Teece, D. J. (2019). The structural reshaping of globalization: Implications for strategic sectors, profiting from innovation, and the multinational enterprise. Journal of International Business Studies, 50(9), 1487-1512.

8. Scherer, A. G., \& Palazzo, G. (2011). The new political role of business in a globalized world: A review of a new perspective on CSR and its implications for the firm, governance, and democracy. Journal of management studies, 48(4), 899-931.

9. Petricevic, O., \& Teece, D. J. (2019). The structural reshaping of globalization: Implications for strategic sectors, profiting from innovation, and the multinational enterprise. Journal of International Business Studies, 50(9), 1487-1512.

10. Dos Santos, L. M. (2020). The Discussion of Communicative Language Teaching Approach in Language Classrooms. Journal of Education and e-Learning Research, 7(2), 104-109.

11. Lestariyana, R. P. D., \& Widodo, H. P. (2018). Engaging young learners of English with digital stories: Learning to mean. Indonesian Journal of Applied Linguistics, 8(2), 489-495.

12. Murdoch, M., \& Muller, T. (2011). The learning explosion. Franklin Covey.

13. Costa, C., Alvelos, H., \& Teixeira, L. (2012). The use of Moodle e-learning platform: a study in a Portuguese University. Procedia Technology, 5, 334-343.

14. Bowen, William G. Higher Education in the Digital Age (2013). Translation from English by Dmitry Kralechkin. - Moscow: Publishing House 'Higher School of Economics', 222.

15. Nariyati, N. P. L. (2020). EFL Pre-Service Teachers' Perception toward the Use of Mobile Assisted Language Learning in Teaching English. International Journal of Language Education, 4(1), 38-47.

16. Chartrand, R. (2016). Advantages and Disadvantages of Using Mobile Devices in a University Language Classroom. Bulletin of the Institute of Foreign Language Education Kurume University, 23, 1-13

17. Tanyeli, N. (2009). The efficiency of online English language instruction on students' reading skills. Procedia-Social and Behavioral Sciences, 1(1), 564-567..

18. Pitoyo, M. D. (2020). Gamification-Based Assessment: The Washback Effect of Quizizz on Students' Learning in Higher Education. International Journal of Language Education, 4(1), 1-10.

19. Sánchez, R. A., \& Hueros, A. D. (2010). Motivational factors that influence the acceptance of Moodle using TAM. Computers in human behavior, 26(6), 1632-1640.

20. Machado, M., \& Tao, E. (2007). Blackboard vs. Moodle: Comparing user experience of learning management systems. In 200737 th annual frontiers in education conference-global engineering: Knowledge without borders, opportunities without passports (pp. S4J-7). IEEE.

21. Savilova, S. L., Smychkova, E. G., Kokhanovskaya, E. V., \& Kropotkina, A. A. (2019). Latest Anglicisms Used in Teaching Russian as a Foreign Language to Contribute to Motivation and Adaptation of Polylingual Students in Russia. In " Humanities and Social Sciences: Novations, Problems, Prospects"(HSSNPP 2019). Atlantis Press.

22. Banalieva, E. R., \& Dhanaraj, C. (2019). Internalization theory for the digital economy. Journal of International Business Studies, 50(8), 1372-1387. 